\title{
Euclidean and Function Space Null-Controllability of Nonlinear Delay Systems with Restrained Controls
}

\author{
Dr. Musa T. Y. Kadzai \\ Department of Mathematics, Modibbo Adama University of Technology, Yola, Nigeria
}

Abstract:The basic tool we use in our investigation is the nonlinear variation of constants formula for delay systems whilst we determine the controllability of nonlinear functional differential systems. This paper also touches on capture in nonlinear functional differential games of pursuit.

Keywords: Delay systems, controllability, variation of constants formula.

\section{Introduction}

Hermes and Lasalle [1] investigated the controllability of the system:

$$
\begin{aligned}
& \dot{x}(t)=A(t) x(t)+B(t) u(t) \\
& x(0)=x^{0}
\end{aligned}
$$

where $\mathrm{x} \in \mathrm{E}^{\mathrm{n}}, \mathrm{A}(\cdot)$ and $\mathrm{B}(\cdot)$ are nxn- and nxm-matrix valued functions, respectively, with components summable over finite real interval and $u(\cdot)$ is vector valued function which is constrained to lie in a compact set $\mathbb{U}$ of $E^{\mathrm{m}}$. They showed that if:

$$
\dot{\mathrm{x}}(\mathrm{t})=\mathrm{A}(\mathrm{t}) \mathrm{x}(\mathrm{t})
$$

is uniformly asymptotically stable and if (1) is controllable with $\mathrm{L}_{2}\left([\sigma, \infty), \mathrm{E}^{\mathrm{m}}\right)$ controls then (1) is null controllable with controls in $\mathbb{U}$. Chukwu [2] examined the nonlinear retarded system:

$$
\begin{aligned}
& \dot{\mathrm{x}}(\mathrm{t})=\mathrm{L}\left(\mathrm{t}, \mathrm{x}_{\mathrm{t}}\right)+\mathrm{B}(\mathrm{t}) \mathrm{u}(\mathrm{t})+\mathrm{f}\left(\mathrm{t}, \mathrm{x}_{\mathrm{t}}, \mathrm{u}(\mathrm{t})\right), \mathrm{t} \geq \sigma \\
& \mathrm{x}_{\sigma}=\varphi \text { in }[-\mathrm{r}, 0]
\end{aligned}
$$

where $\mathrm{B}(\mathrm{t})$ is a continuous nxm-matrix, and for each $\mathrm{t} \in \mathrm{E}$ the linear operator $\varphi \rightarrow \mathrm{L}(\mathrm{t}, \varphi), \varphi \in \mathrm{W}_{2}^{(1)}$ has the form:

$$
L(t, \varphi)=\int_{-r}^{0} d_{s} \eta(t, s) \varphi(s)
$$

where the integral is in the Lebesque-Stieljes sense and $(t, \theta) \rightarrow \eta(t, \theta),(t, \theta) \in E x E$ is a mapping with values in $L_{n n}$, the space of continuous nxn-matrices. It is assumed that $t \rightarrow \eta(t, \theta)$ is continuous for each fixed $\theta \in[-r, 0]$ and $\theta \rightarrow \eta(t, \theta)$ is of bounded variation on $[-r, 0]$ for each fixed $t \in E$. Moreover, $\eta(t, \theta)=0, \theta \geq 0, \eta(t, \theta)=$ $\eta(\mathrm{t},-\mathrm{r}), \theta \leq \mathrm{r}$ and $\theta \rightarrow \eta(\mathrm{t}, \theta)$ is left continuous on $[-\mathrm{r}, 0]$ satisfying:

$$
\underset{s \in E}{\operatorname{Var}} \eta(t, s) \leq \rho(t), \quad t \in E
$$

where $\rho(t)$ is locally integrable. The function:

$$
f:[\sigma, \infty) x W_{2}^{(1)} x E^{m} \rightarrow E^{n}
$$

is continuous and uniformly Lipschitzian in the last two arguments. He showed that if:

(i)

$$
\begin{aligned}
& \text { the system: } \\
& \dot{\mathrm{x}}(\mathrm{t})=\mathrm{L}\left(\mathrm{t}, \mathrm{x}_{\mathrm{t}}\right)+\mathrm{B}(\mathrm{t}) \mathrm{u}(\mathrm{t}) \\
& \mathrm{x}_{\sigma}=\varphi \in \mathrm{W}_{2}^{(1)}\left([-\mathrm{r}, 0], \mathrm{E}^{\mathrm{n}}\right)
\end{aligned}
$$

where $\mathrm{u} \in \mathbb{U} \subseteq \mathrm{L}_{2}^{\text {loc }}([\sigma, \infty), \mathrm{U}), \mathrm{U} \subseteq \mathrm{E}^{\mathrm{m}}, 0 \in \mathrm{Int} \mathrm{U}$ is complete; that is, zero is in the interior of the reachable set of (7), and 
(ii) the free system:

$$
\dot{\mathrm{x}}(\mathrm{t})=\mathrm{L}\left(\mathrm{t}, \mathrm{x}_{\mathrm{t}}\right)
$$

is uniformly asymptotically stable so that there exist some constants $\mathrm{k} \geq 1, \alpha>0$ such that every solution of (8) satisfies the boundedness condition:

$$
\left\|\mathrm{x}_{\mathrm{t}}(\sigma, \varphi)\right\| \leq \mathrm{k}\|\varphi\| \mathrm{e}^{-\alpha(\mathrm{t}-\sigma)}, \mathrm{t} \geq \sigma
$$

and if:

(iii)

$$
\begin{gathered}
\mathrm{f}(\mathrm{t}, 0,0)=0 \\
\mathrm{f}(\mathrm{t}, \varphi, 0)=\mathrm{f}_{1}(\mathrm{t}, \varphi)+\mathrm{f}_{2}(\mathrm{t}, \varphi)
\end{gathered}
$$

where

$$
\left|f_{1}(t, \varphi)\right| \leq \pi(t)\|\varphi\|, \quad\left|f_{2}(t, \varphi)\right| \leq \varepsilon\|\varphi\|
$$

with

$$
\int_{\sigma}^{\infty} \pi(\mathrm{t}) \mathrm{dt} \leq \infty, \varepsilon=\frac{\alpha}{2 \mathrm{k}}, \mathrm{t} \geq \sigma, \varphi \in \mathrm{W}_{2}^{(1)}
$$

Chukwu [3] investigated controllability under unpredictable disturbances whose state space is the Sobolev space, $\mathrm{W}_{2}^{(1)}\left([\sigma, \infty), \mathrm{E}^{\mathrm{n}}\right)$, with dynamical equation;

$$
\dot{x}(t)=L\left(t, x_{t}\right)-p(t)+q(t), t \in[\sigma, \infty)
$$

where $\mathrm{p}(\cdot) \in \mathrm{L}_{2}([\sigma, \mathrm{t}], \mathrm{P}), \mathrm{P} \subseteq \mathrm{E}^{\mathrm{m}}, \mathrm{q}(\cdot) \in \mathrm{L}_{2}([\sigma, \mathrm{t}], \mathrm{Q}), \mathrm{Q} \subseteq \mathrm{E}^{\mathrm{m}}, \mathrm{L}(\mathrm{t}, \varphi)$ satisfies the conditions in (3). Here $\mathrm{q}$ is the quarry control and $\mathrm{p}$ is the control strategy for the pursuer. The target is either a subset of $\mathrm{W}_{2}^{(1)}$, a point in $\mathrm{W}_{2}^{(1)}$, a subset of $\mathrm{E}^{\mathrm{n}}$, or a point of $\mathrm{E}^{\mathrm{n}}$. There is capture if the initial function can be forced to the target by the pursuer no matter what the quarry does. He showed that the associated linear retarded functional differential equation:

$$
\begin{aligned}
& \dot{x}(t)=L\left(t, x_{t}\right)-u(t), t \geq \sigma \\
& x_{\sigma}=\varphi \in W_{2}^{(1)}\left([-r, 0], E^{n}\right) \\
& u(t) \in \mathbb{U} \\
& P_{-}^{*} Q=\mathbb{U}=\{x: x+Q \subseteq P\}
\end{aligned}
$$

is controllable if and only if there is capture for game (12).

Shanholt [4] examined the system:

$$
\dot{y}(t)=f\left(t, y_{t}\right)+g\left(t, y_{t}\right)
$$

where $f, g: \Gamma \rightarrow E^{n}$ are continuous in $\Gamma=(\tau, \infty) \times \Lambda, \Lambda$ is open in $C\left([-r, 0], E^{n}\right)$ and $f(t, \varphi)$ has continuous Frechet derivative $\mathrm{f}^{\prime}(\mathrm{t}, \varphi)$ with respect to $\varphi \in \Lambda$. By examining the linear variational equation:

$$
\dot{\mathrm{z}}(\mathrm{t})=\mathrm{f}^{\prime}\left(\mathrm{t}, \mathrm{x}_{\mathrm{t}}(\sigma, \varphi)\right) \mathrm{z}_{\mathrm{t}}, \mathrm{t} \in[\sigma, \infty]
$$

with respect to $\mathrm{x}(\sigma, \varphi)$, the solution of the nonlinear system:

$$
\begin{aligned}
& \dot{x}(t)=f\left(t, x_{t}\right), t \geq \sigma \\
& x_{\sigma}=\varphi
\end{aligned}
$$


he developed a nonlinear Alekseev like variation of constants formula for the nonlinear retarded system. $\mathrm{He}$ showed that the solution of the perturbed nonlinear retarded system (15) is given by:

$$
\mathrm{y}_{\mathrm{t}}(\sigma, \varphi)=\mathrm{x}_{\mathrm{t}}(\sigma, \varphi)+\int_{\sigma}^{\mathrm{t}} \mathrm{T}(\mathrm{t}, \mathrm{s}) \mathrm{Y}_{0} \mathrm{~g}\left(\mathrm{~s}, \mathrm{y}_{\mathrm{s}}(\sigma, \varphi)\right) \mathrm{ds}
$$

where $\mathrm{x}(\sigma, \varphi)$ is the solution of the nonlinear system:

$$
\dot{x}(t)=f\left(t, x_{t}\right)
$$

and $\mathrm{Y}_{0}$ is the nxn- matrix function defined by the relation:

$$
\mathrm{Y}_{0}(\theta)=\left\{\begin{array}{l}
0,-\mathrm{r} \leq \theta<0 \\
\mathrm{I}, \theta=0
\end{array}\right.
$$

(I - identity matrix).

In this paper we use the variation of constants formula for nonlinear systems as developed in Shanholt [4] to investigate the controllability of a retarded system:

$$
\dot{x}(t)=g\left(t, x_{t}\right)+B(t) u(t)
$$

where $\mathrm{g}(\mathrm{t}, \varphi)$ is nonlinear. We employ the method developed in Chukwu [5] to establish function space null-controllability with constraints of the nonlinear retarded system. This paper is in four sections. The first section is introduces the subject and the second section establishes notations and definitions. Section three establishes Euclidean and Function space null-controllability while section four studies both Euclidean and Function space capture in nonlinear retarded differential games of pursuit.

\section{Notations and Definitions}

Let $\mathrm{E}^{\mathrm{n}}$ denote the $\mathrm{n}$-dimensional Euclidean space. For $\sigma, \mathrm{t}_{1} \in \mathrm{E}$, the symbol $\mathrm{L}_{2}\left(\left[\sigma, \mathrm{t}_{1}\right], \mathrm{E}^{\mathrm{n}}\right)$ denotes the space of square integrable functions from the interval $\left[\sigma, t_{1}\right]$ into $E^{\text {n }}$. We shall denote the Sobolev space of all absolutely continuous functions $\mathrm{x}:\left[\sigma, \mathrm{t}_{1}\right] \rightarrow \mathrm{E}^{\mathrm{n}}$ whose derivative $\dot{\mathrm{x}}(\cdot) \in \mathrm{L}_{2}\left(\left[\sigma, \mathrm{t}_{1}\right], \mathrm{E}^{\mathrm{n}}\right)$ by $\mathrm{W}_{2}^{(1)}\left(\left[\sigma, \mathrm{t}_{1}\right], \mathrm{E}^{\mathrm{n}}\right)$. Let $\mathrm{r}>0$ be given. For functions $\mathrm{x}:\left[\sigma-\mathrm{r}, \mathrm{t}_{1}\right] \rightarrow \mathrm{E}^{\mathrm{n}}$ and $\mathrm{t} \in\left[\sigma, \mathrm{t}_{1}\right]$ we use $\mathrm{x}_{\mathrm{t}}$ to denote the function on $[-\mathrm{r}, 0]$ defined by:

$$
x_{t}(\theta)=x(t+\theta),-r \leq \theta \leq 0 .
$$

Consider the nonlinear delay functional differential system of the form:

$$
\begin{aligned}
& \dot{\mathrm{x}}(\mathrm{t})=\mathrm{g}\left(\mathrm{t}, \mathrm{x}_{\mathrm{t}}\right), \mathrm{t} \geq \sigma \\
& \mathrm{x}_{\sigma}=\varphi \in \mathrm{W}_{2}^{(1)}\left([-\mathrm{r}, 0], \mathrm{E}^{\mathrm{n}}\right)
\end{aligned}
$$

where we assume as basic that $\mathrm{g}: \mathrm{Ex} \mathrm{W}_{2}^{(1)} \rightarrow \mathrm{E}^{\mathrm{n}}$ is continuous and has continuous Frechet derivative with respect to $\mathrm{x}_{\mathrm{t}}(\sigma, \varphi)$ and where $\mathrm{g}(\mathrm{t}, \varphi)$ is locally Lipschitzian in $\varphi$ in each compact set of E x $\mathrm{W}_{2}^{(1)}$. Let $\dot{\mathrm{x}}(\mathrm{t})$ denote the right-hand derivative of $\mathrm{x}(\mathrm{u})$ at $\mathrm{u}=\mathrm{t}$. For any $\sigma \in \mathrm{E}$, and $\varphi \in \mathrm{W}_{2}^{(1)}$ we say that $\mathrm{x}(\sigma, \varphi)$ is a solution of (22) with initialt function $\varphi$ at $\sigma$ if there exists an a $>0$ such that $\mathrm{x}(\sigma, \varphi) \in \mathrm{W}_{2}^{(1)}\left([\sigma-\mathrm{r}, \mathrm{a}+\sigma], \mathrm{E}^{\mathrm{n}}\right), \mathrm{x}_{\sigma}=$ $\varphi$ and $\mathrm{x}(\sigma, \varphi)$ satisfies (22) for $\mathrm{t} \in[\sigma, \sigma+\mathrm{a}]$. From the above assumptions (22) has a unique solution $\mathrm{x}(\sigma, \varphi)$ which depends continuously on $\sigma, \varphi$ and on $\mathrm{t} \in \mathrm{E}$. We also assume as basic that:

$$
g(t, 0)=0 \text { for } t \geq \sigma
$$

and that the solution $\mathrm{x}(\sigma, \varphi)$ of (22) satisfies $\mathrm{x}(\sigma, \varphi)=0$ if, and only if $\varphi \equiv 0$.

In the system:

$$
\dot{\mathrm{x}}(\mathrm{t})=\mathrm{g}\left(\mathrm{t}, \mathrm{x}_{\mathrm{t}}\right)+\mathrm{B}(\mathrm{t}) \mathrm{u}(\mathrm{t})
$$

let $\mathrm{g}$ satisfy the conditions of (23) and let $\mathrm{B}(\mathrm{t})$ be a continuous function such that: 
$\|\mathrm{B}(\mathrm{t})\| \leq \rho(\mathrm{t})$

where $\rho(t)$ is a continuous function on $[0, \infty)$ satisfying:

$$
\int_{0}^{\infty} \rho(\mathrm{t}) \mathrm{dt}<\infty
$$

and where $\|\cdot\|$ denotes a matrix norm. Let $u \in \mathbb{U}=\mathrm{L}_{2}\left([\sigma, \infty), \mathrm{C}^{\mathrm{m}}\right)$ where $\mathrm{C}^{\mathrm{m}}=\left\{\mathrm{u} \in \mathrm{E}^{\mathrm{m}}:\left|\mathrm{u}_{\mathrm{j}}\right| \leq 1, \mathrm{j}=1, \cdots, \mathrm{m}\right\}$. Corresponding to each solution $\mathrm{x}(\sigma, \varphi)$ of (23) we define a linear delay functional differential system:

$$
\dot{\mathrm{z}}(\mathrm{t})=\mathrm{f}^{\prime}\left(\mathrm{t}, \mathrm{x}_{\mathrm{t}}(\sigma, \varphi)\right) \mathrm{z}_{\mathrm{t}}
$$

For each $t \in J(\sigma, x)$, the maximal interval of existence of $x(\sigma, \varphi)$. The system (28) is called the linear variational equation of (23) with respect to $\mathrm{x}(\sigma, \varphi)$. For any fixed $\sigma$ and $\mathrm{t} \geq \sigma, \mathrm{z}(\sigma, \cdot)(\mathrm{t})$ is a continuous linear operator from $\mathrm{W}_{2}^{(1)}$ into $\mathrm{E}^{\mathrm{n}}$. Thus, throughout this work, to the linear system (28), we shall associate a family of linear operatorsT $(\mathrm{t}, \sigma)(\cdot): \mathrm{W}_{2}^{(1)} \rightarrow \mathrm{W}_{2}^{(1)}, \mathrm{t} \geq \sigma$, by defining for each $\varphi \in \mathrm{W}_{2}^{(1)}$ :

$$
\mathrm{T}(\mathrm{t}, \sigma) \varphi=\mathrm{z}_{\mathrm{t}}(\sigma, \varphi) .
$$

For any initial function $\varphi \in \mathrm{W}_{2}^{(1)}\left([-\mathrm{r}, 0], \mathrm{E}^{\mathrm{n}}\right)$ we may define a solution of (28) with initial function $\varphi$ at $\sigma$ by $\mathrm{z}(\sigma, \varphi)$. Therefore, if the $\mathrm{n} \mathrm{x}$ matrix function $\mathrm{Y}_{0}$ is defined by:

$$
\mathrm{Y}_{0}(\theta)=\left\{\begin{array}{lr}
0, & -\mathrm{r} \leq \theta<0 \\
\mathrm{I}, & \theta=0
\end{array}\right.
$$

where $I$ is the identity matrix, then the operator $T(t, \sigma)$ may be defined on the columns of $Y_{0}$. If $\mathrm{B}(\mathrm{t}), \mathrm{u}(\mathrm{t})$ satisfy the conditions in (25), then $\mathrm{x}(\sigma, \varphi, u)$ is the solution of (25) with initial function $\varphi \in \mathrm{W}_{2}^{(1)}$ at $\sigma \in \mathrm{E}$, if and only if $\mathrm{x}(\sigma, \varphi, \mathrm{u})$ satisfies the integral equation:

$$
x_{t}(\sigma, \varphi, u)=x_{t}(\sigma, \varphi)+\int_{\sigma}^{t} T(t, s) Y_{0} B(s) u(s) d s, \quad t \geq \sigma
$$

where $\mathrm{x}_{\mathrm{t}}(\sigma, \varphi)$ is the solution of $(23)$.

\section{Definition 2.1}

The system (23) is globally exponentially asymptotically stable if there exists an $L>0, c>0$ such that the solution $\mathrm{x}(\sigma, \varphi)$ of $(23)$ satisfies, $\mathrm{x}_{\sigma}(\sigma, \varphi)=\varphi$ and:

$$
\left\|\mathrm{x}_{\mathrm{t}}(\sigma, \varphi)\right\| \leq \mathrm{L} \mathrm{e} \mathrm{e}^{-\mathrm{c}(\mathrm{t}-\sigma)}\|\varphi\|, \quad \mathrm{t} \in[\sigma, \infty) .
$$

\section{Definition 2.2}

The system (25) is proper on an interval $(\sigma, \mathrm{t}]$ if $\mathrm{C}^{\mathrm{T}} \mathrm{T}(\mathrm{t}, \mathrm{s}) \operatorname{IB}(\mathrm{s})=0$ a. e. $\mathrm{s} \in[\sigma, \mathrm{t}]$, for each $\varphi \in \mathrm{W}_{2}^{(1)}$ implies $C=0$, where $C^{T}$ denotes the transpose of $C$ inE $E^{n}$. If (23) is proper on each interval $[\sigma, t], t \geq \sigma$ we say the system is proper.

\section{Definition 2.3}

The system (25) is null-controllable with constraints if given any initial state $\varphi \in \mathrm{W}_{2}^{(1)}$, there exists $\mathrm{t}_{1} \geq \sigma$ and an admissible control $\mathrm{u} \in \mathbb{U}$ such that the solution $\mathrm{x}(\sigma, \varphi, \mathrm{u})$ satisfies $\mathrm{x}_{\sigma}(\sigma, \varphi, \mathrm{u})=\varphi$ and $\mathrm{x}\left(\mathrm{t}_{1}, \sigma, \varphi, \mathrm{u}\right)=0$.

\section{Definition 2.4}

The system (25) is null-controllable if given any initial state $\varphi \in \mathrm{W}_{2}^{(1)}\left([-r, 0], \mathrm{E}^{\mathrm{n}}\right)$, there existst ${ }_{1} \geq \sigma$ And an admissible control $\mathrm{u} \in \mathrm{L}_{2}\left([\sigma, \infty), \mathrm{E}^{\mathrm{m}}\right)$ such that the solution $\mathrm{x}(\sigma, \varphi, \mathrm{u})$ satisfies $\mathrm{x}_{\sigma}(\sigma, \varphi, \mathrm{u})=$ $\varphi$ and $\mathrm{x}\left(\mathrm{t}_{1}, \sigma, \varphi, \mathrm{u}\right)=0$. 


\section{Controllability Results}

The Euclidean space reachable set of (25) is the set:

$$
\mathbb{R}(\mathrm{t}, \sigma)=\left\{\int_{\sigma}^{\mathrm{t}} \mathrm{T}(\mathrm{t}, \mathrm{s}) \mathrm{B}(\mathrm{s}) \mathrm{u}(\mathrm{s}) \mathrm{ds}: \mathrm{u} \in \mathbb{U}\right\}
$$

Respectively, the function space reachable set is given by:

$$
\mathbb{A}(t, \sigma)=\left\{\int_{\sigma}^{t} T(t, s) Y_{0} B(s) u(s) d s: u \in \mathbb{U}\right\}
$$

where $\mathrm{u} \in \mathbb{U}$ is as given in (25) and $\mathrm{Y}_{0}$ is as defined by $(30), \mathrm{t} \geq \sigma$ and $\varphi \in \mathrm{W}_{2}^{(1)}\left([-\mathrm{r}, 0], \mathrm{E}^{\mathrm{n}}\right)$.

Theorem 3.1

The system (25) is proper on $[\sigma, t]$ if, and only if $0 \in \operatorname{Int} \mathbb{R}(t, \sigma)$.

Proof:

Given that $\mathbb{U}=\mathrm{L}_{2}\left([\sigma, \infty), \mathrm{C}^{\mathrm{m}}\right)$ where $\mathrm{C}^{\mathrm{m}}=\left\{\mathrm{u} \in \mathrm{E}^{\mathrm{m}}:\left|\mathrm{u}_{\mathrm{j}}\right| \leq 1, \mathrm{j}=1, \cdots, \mathrm{m}\right\}$. $\mathbb{U}$ is weak* compact. Let $\mathrm{Y}(\mathrm{s})=\mathrm{T}(\mathrm{t}, \mathrm{s}) \mathrm{B}(\mathrm{s})$ and for the sequence $\left\{\mathrm{u}_{\mathrm{i}}\right\}_{1}^{\infty} \subseteq \mathbb{U}$ let

$$
s_{i}=\int_{\sigma}^{t} Y(s) u_{i}(s) d s \in \mathbb{R}(t, \sigma), \quad i=1,2, \cdots
$$

We may extract a convergent subsequence, $\left\{\mathrm{u}_{\mathrm{k}}\right\}_{1}^{\infty}$ say, such that $\mathrm{u}_{\mathrm{k}} \rightarrow \mathrm{u} \in \mathbb{U}$, and

$$
\lim _{\mathrm{i} \rightarrow \infty} \int_{\sigma}^{\mathrm{t}} \mathrm{Y}(\mathrm{s}) \mathrm{u}_{\mathrm{k}}(\mathrm{s}) \mathrm{d} \mathrm{s} \rightarrow \int_{\sigma}^{\mathrm{t}} \mathrm{Y}(\mathrm{s}) \mathrm{u}(\mathrm{s}) \mathrm{d} s
$$

then

$$
\lim _{\mathrm{i} \rightarrow \infty} \mathrm{s}_{\mathrm{i}}=\mathrm{s} \in \mathbb{R}(\mathrm{t}, \sigma) .
$$

Hence $\mathbb{R}(t, \sigma)$ is closed. Furthermore, consider the controls $u_{1}, u_{2} \in \mathbb{U}, 0<\alpha<1$, we find that

$$
\begin{aligned}
& \alpha \int_{\sigma}^{t} Y(s) u_{1}(s) d s+(1-\alpha) \int_{\sigma}^{t} Y(s) u_{2}(s) d s \\
& =\int_{\sigma}^{t} Y(s)\left[\alpha u_{1}(s)+(1-\alpha) u_{2}(s)\right] d s .
\end{aligned}
$$

But for each $\mathrm{j}$ satisfying $1 \leq \mathrm{j} \leq \mathrm{m}$,

$$
\left|\alpha u_{1 j}(s)+(1-\alpha) u_{2 j}(s)\right| \leq \alpha\left|u_{1 j}(s)\right|+(1-\alpha)\left|u_{2 j}(s)\right|=1 \text {. }
$$

It follows that $\alpha \mathrm{u}_{1}(\mathrm{~s})+(1-\alpha) \mathrm{u}_{2}(\mathrm{~s}) \in \mathbb{U}$ so that:

$$
\int_{\sigma}^{t} \mathrm{Y}(\mathrm{s})\left[\alpha \mathrm{u}_{1}(\mathrm{~s})+(1-\alpha) \mathrm{u}_{2}(\mathrm{~s})\right] \mathrm{d} \mathrm{s} \in \mathbb{R}(\mathrm{t}, \sigma)
$$

Hence, $\mathbb{R}(t, \sigma)$ is convex, so $\mathbb{R}(t, \sigma)$ is closed and convex.

Consider a point $x_{1}$ on the boundary of $\mathbb{R}(t, \sigma)$. Since the reachable set is closed and convex, there is a support plane $\pi$ through $\mathrm{x}_{1}$. That is $\mathrm{C}^{\mathrm{T}}\left(\mathrm{x}-\mathrm{x}_{1}\right) \leq 0$ for each $\mathrm{x} \in \mathbb{R}(\mathrm{t}, \sigma)$, where $\mathrm{C} \neq 0$ is an outward normal to $\pi$. If $\mathrm{u}_{1}$ is the corresponding control to $\mathrm{x}_{1}$ then we have:

$$
\mathrm{C}^{\mathrm{T}} \int_{\sigma}^{\mathrm{t}} \mathrm{Y}(\mathrm{s}) \mathrm{u}(\mathrm{s}) \mathrm{ds} \leq \mathrm{C}^{\mathrm{T}} \int_{\sigma}^{\mathrm{t}} \mathrm{Y}(\mathrm{s}) \mathrm{u}_{1}(\mathrm{~s}) \mathrm{ds} \text {, for each } \mathrm{u} \in \mathbb{U} \text {. }
$$

Since $\mathrm{C}^{\mathrm{m}}$ is unit cube, this last inequality will hold for each $\mathrm{u} \in \mathrm{C}^{\mathrm{m}}$ if, and only if

$$
\mathrm{C}^{\mathrm{T}} \int_{\sigma}^{\mathrm{t}} \mathrm{Y}(\mathrm{s}) \mathrm{u}(\mathrm{s}) \mathrm{ds} \leq \int_{\sigma}^{\mathrm{t}}\left|\mathrm{C}^{\mathrm{T}} \mathrm{Y}(\mathrm{s}) \mathrm{u}_{1}(\mathrm{~s})\right| \mathrm{d} s=\int_{\sigma}^{\mathrm{t}}\left|\mathrm{C}^{\mathrm{T}} \mathrm{Y}(\mathrm{s})\right| \mathrm{ds} .
$$

And $u_{1}(s)=\operatorname{sgn} C^{T} Y(s)$. Since we always have $0 \in \mathbb{R}(t, \sigma)$, if 0 is not in the interior, then it is on the boundary. This is equivalent to: 


$$
0=\int_{\sigma}^{t}\left|C^{T} Y(s)\right| \text { ds so that } C^{T} Y(s)=0 \text { a.e.s } \in[\sigma, t] .
$$

Contradiction. Hence, the system is proper. This completes the proof.

Theorem 3.2: Suppose,

i) The solution $\mathrm{x}(\sigma, \varphi)$ of (23) is globally exponentially asymptotically stable and

ii) The system (25) is proper,

then the system (25) is Euclidean space null-controllable with constraints.

Proof:

By the variation of constants formula, the solution of (25) is given as:

$$
x(t, \sigma, \varphi, u)=x(t, \sigma, \varphi)+\int_{\sigma}^{t} T(t, s) B(s) u(s) d s: t \geq \sigma
$$

$$
x\left(t_{1}, \sigma, \varphi, u\right)=x\left(t_{1}, \sigma, \varphi\right)+\int_{\sigma}^{t_{1}} T\left(t_{1}, s\right) B(s) u(s) d s
$$

and

$$
x\left(t_{1}, \sigma, \varphi\right)=-\int_{\sigma}^{t_{1}} T\left(t_{1}, s\right) B(s) u(s) d s .
$$

Now define $\mathrm{H}$ as follows:

$$
H\left(t_{1}\right)=\left\{x\left(t_{1}, \sigma, \varphi\right)+\int_{\sigma}^{t_{1}} T\left(t_{1}, s\right) B(s) u(s) d s: u \in \mathbb{U}, \varphi \in W_{2}^{(1)}, x_{\sigma}=\varphi\right\}
$$

Clearly, $\mathrm{H}\left(\mathrm{t}_{1}\right)$ is a sum of two sets, the first of which is contained in the second part, the Euclidean space reachable set.

By definition the domain $\mathcal{C}$ of null-controllability is the collection $\varphi \in \mathrm{W}_{2}^{(1)}$ such that for any initial state $\varphi$ there exists $\mathrm{at}_{1}$ and some $\mathrm{u} \in \mathbb{U}$ such that the solution $\mathrm{x}(\sigma, \varphi, \mathrm{u})$ of (25) satisfies $\mathrm{x}_{\sigma}=\varphi$ and $\mathrm{x}\left(\mathrm{t}_{1}, \sigma, \varphi, \mathrm{u}\right)=0$. Hence $\mathcal{C}$ is the subset of $\mathrm{W}_{2}^{(1)}$ such that:

$$
\mathrm{x}\left(\mathrm{t}_{1}, \sigma, \mathcal{C}\right)=\{\mathrm{x}(\mathrm{t}, \sigma, \varphi): \varphi \in \mathcal{C}, \mathrm{x}(\sigma, \varphi) \text { is a solution of }(23)\}
$$

Since (25) is proper $0 \in \mathbb{R}(\mathrm{t}, \sigma)$ for each $\mathrm{t}$. Hence $0 \in \operatorname{Int} \mathcal{C}$. Indeed, suppose not, since $0 \in \mathcal{C}$ there is a sequence $\left\{\varphi_{\mathrm{m}}\right\}_{1}^{\infty} \subseteq \mathrm{W}_{2}^{(1)}$ such that $\varphi_{\mathrm{m}} \rightarrow 0$ as $\mathrm{m} \rightarrow \infty$ and no $\varphi_{\mathrm{m}}$ is in $\mathcal{C}$ so that $\varphi_{\mathrm{m}} \neq 0$. Suppose $\mathrm{x}\left(\mathrm{t}, \sigma, \varphi_{\mathrm{m}}\right)=\mathrm{x}_{\mathrm{m}}$. Then $\mathrm{x}_{\mathrm{m}} \neq 0$, and by continuity $\mathrm{x}_{\mathrm{m}} \rightarrow \mathrm{x}(\mathrm{t}, \sigma, 0)=0$ as $\mathrm{m} \rightarrow \infty$. Hence 0 is not in the interior of the reachable set, $\mathrm{a}$ contradiction. Hence 0 is in the interior of $\mathcal{C}$. Since the 0 function is in the interior of , there is an open ball $\mathcal{P} \subseteq \mathrm{W}_{2}^{(1)}$ around 0 which is contained in $\mathcal{C}$.

In (25) set $\mathrm{u}=0$ on $[\sigma, \infty)$. Then the solution $\mathrm{x}(\sigma, \varphi, \mathrm{u})$ of $(25)$ with initial state $\varphi$ is the solution of (23). By condition (i) of Theorem 3.2 every solution of (23) satisfies:

$$
\mathrm{x}_{\sigma}=\varphi \text { and }\left\|\mathrm{x}_{\mathrm{t}}(\sigma, \varphi)\right\| \leq \mathrm{Le}^{-\mathrm{c}(\mathrm{t}-\sigma)}\|\varphi\|
$$

$\epsilon \mathcal{P} \subseteq \mathcal{C}$. With $\mathrm{x}_{\mathrm{t}_{1}}(\sigma, \varphi) \in \mathcal{C}$ as an initial function there are a $\mathrm{t}_{2}$ and control $\mathrm{u} \in \mathbb{U}$ such that the solution satisfies:

$$
\mathrm{x}_{\mathrm{t}_{2}}\left(\sigma, \mathrm{x}_{\mathrm{t}_{1}}\right)=\mathrm{x}_{\mathrm{t}_{1}} \text { and } \mathrm{x}_{\mathrm{t}_{2}}\left(\sigma, \mathrm{x}_{\mathrm{t}_{1}}, \mathrm{u}\right)=0 \text {. }
$$

This completes the proof.

Definition 2.3

The system (25) is said to be complete on $[\sigma, t]$ if, and only if:

$$
0 \in \mathrm{A}(\mathrm{t}, \sigma), \mathrm{t} \geq \sigma+\mathrm{r} .
$$


The system (25) is complete if it is complete on each interval $[\sigma, t], t \geq \sigma+r$. It is complete with constraints if $0 \in \operatorname{Int} A(t, \sigma), u \in \mathbb{U}, t \geq \sigma+r$ where $\mathbb{U}$ is as defined in (25).

Let $\mathrm{g}^{\prime}\left(\mathrm{t}, \mathrm{x}_{\mathrm{t}}\right)$ be the Frechet derivative of $\mathrm{g}\left(\mathrm{t}, \mathrm{x}_{\mathrm{t}}\right)$ with respect to $\mathrm{x}_{\mathrm{t}}(\sigma, \varphi)$, where $\mathrm{x}(\sigma, \varphi)$ is the solution of (23). Consider the linear control system:

$$
\dot{\mathrm{z}}(\mathrm{t})=\mathrm{g}^{\prime}\left(\mathrm{t}, \mathrm{x}_{\mathrm{t}}(\sigma, \varphi)\right) \mathrm{z}_{\mathrm{t}}+\mathrm{B}(\mathrm{t}) \mathrm{u}(\mathrm{t})
$$

where $\mathrm{B}(\mathrm{t})$ and $\mathrm{u}(\mathrm{t})$ are as given in (25). Consider also the free system:

$$
\dot{\mathrm{z}}(\mathrm{t})=\mathrm{g}^{\prime}\left(\mathrm{t}, \mathrm{x}_{\mathrm{t}}(\sigma, \varphi)\right) \mathrm{z}_{\mathrm{t}} .
$$

The solution of (52) is given by:

$$
z_{t}(\sigma, \varphi, u)=z_{t}(\sigma, \varphi)+\int_{\sigma}^{t} T(t, s) Y_{0} B(s) u(s) d s
$$

for $t \geq \sigma, \varphi \in \mathrm{W}_{2}^{(1)}, \mathrm{Y}_{0}$ as in (30) and $\mathrm{T}(\mathrm{t}, \sigma)$ is the family of linear operators associated with (53); where the integral equation (54) is an integral equation in $\mathrm{E}^{\mathrm{n}}$ and is to be interpreted as:

$$
\mathrm{z}_{\mathrm{t}}(\theta)=[\mathrm{T}(\mathrm{t}, \sigma) \varphi](\theta)+\int_{\sigma}^{\mathrm{t}}\left[\mathrm{T}(\mathrm{t}, \mathrm{s}) \mathrm{Y}_{0}\right](\theta) \mathrm{B}(\mathrm{s}) \mathrm{u}(\mathrm{s}) \mathrm{ds}
$$

for $t \geq \sigma,-r \leq \theta \leq 0$.For a derivation of (54) see Hale [6, pp 80-86]. Consequently, the function space reachable set of (52) is given by:

$$
\mathrm{A}(\mathrm{t}, \sigma)=\left\{\int_{\sigma}^{\mathrm{t}} \mathrm{T}(\mathrm{t}, \mathrm{s}) \mathrm{Y}_{0} \mathrm{~B}(\mathrm{~s}) \mathrm{u}(\mathrm{s}) \mathrm{ds}: \mathrm{u} \in \mathrm{L}_{2}\left([\sigma, \infty), \mathrm{E}^{\mathrm{m}}\right)\right\} .
$$

Theorem 3.4

The system (52) is complete on $[\sigma, t], t \geq \sigma+r$ if, and only if (52) is controllable on $[\sigma, t], t \geq \sigma+r$.

Proof:

We note that $A(t, \sigma)$ is a subspace of $W_{2}^{(1)}$. Assume (52) is controllable on $[\sigma, t]$. Then $A(t, \sigma)=$ $\mathrm{W}_{2}^{(1)}, \mathrm{t} \geq \sigma+\mathrm{r}$. So that $0 \in \operatorname{Int} \mathrm{A}(\mathrm{t}, \sigma)$ for each $\mathrm{t} \geq \sigma+\mathrm{r}$.

Conversely, assume that (52) is complete on $[\sigma, t], t \geq \sigma+r$. Then $0 \in \operatorname{Int} A(t, \sigma)$. Since $A(t, \sigma)$ is a subspace this implies that:

$$
A(t, \sigma)=W_{2}^{(1)}, t \geq \sigma+r
$$

This completes the proof.

Theorem 3.5

The system (25) is complete if, and only if, the system (52) is complete.

Proof:

Assume he system (52) is complete. This is equivalent to $0 \in \operatorname{Int} A(t, \sigma), t \geq \sigma+r$. Since the function space reachable set of (25) is the same as the function space reachable set of (52), it follows that the system (25) is complete. This observation completes the proof.

Corollary 3.6

Let $B^{+}(t)$ denote the Moore-Penrose generalized inverse, as in Luenberger [7], of $B(t), t \in$ E. Suppose that the map $t \rightarrow B^{+}(t), t \in E$ is essentially bounded on each interval $[t-r, t]$ and rank $B(t)=n$ on each interval $[t-r, t]$. Then (52) is complete on each interval $[\sigma, t], t \geq \sigma+r$.

Proof:

By theorem 3.1 of Luenberger [7], (52) is controllable on each interval $[\sigma, t], t \geq \sigma+r$ if, and only if rank B $=\mathrm{n}$ on each interval $[t-r, t]$. By theorem 3.4 the system (52) is complete on $[\sigma, t], t \geq \sigma+r$ if, and only if (52) is controllable on $[\sigma, t], t \geq \sigma+r$. This completes the proof.

\section{Remark 3.7}



matrix

As a consequence of Corollary 3.6, (52) is complete if, and only if rank B =n, when B is a constant Theorem 3.8: Suppose

(i) the solution $\mathrm{x}(\sigma, \varphi)$ of (23) is globally exponentially asymptotically stable;

(ii) the system (25) is complete;

then the system (25) is function space null-controllable with constraints.

Proof:

The proof is skipped as it is similar to that of theorem 3.2.

Example 3.8

We consider the homogeneous nonlinear differential difference equation:

$$
\begin{aligned}
& \dot{\mathrm{x}}(\mathrm{t})=\mathrm{Ax}(\mathrm{t})+\mathrm{B}[\mathrm{x}(\mathrm{t}-\mathrm{r})]^{2}:=\mathrm{g}\left(\mathrm{t}, \mathrm{x}_{\mathrm{t}}\right) \\
& \mathrm{x}_{\sigma}=\varphi \in \mathrm{W}_{2}^{(1)}
\end{aligned}
$$

has a nontrivial solution if, and only if

$$
\lambda-\mathrm{A}-\mathrm{Be}^{-\lambda \mathrm{r}}=0 .
$$

However, we are interested in the equation defined by the Frechet derivative given by

$$
\dot{\mathrm{z}}(\mathrm{t})=\mathrm{g}^{\prime}\left(\mathrm{t}, \mathrm{x}_{\mathrm{t}}\right) \mathrm{z}_{\mathrm{t}}
$$

And the controlled equation

$$
\dot{\mathrm{z}}(\mathrm{t})=\mathrm{g}^{\prime}\left(\mathrm{t}, \mathrm{x}_{\mathrm{t}}\right) \mathrm{z}_{\mathrm{t}}+\mathrm{Cu}(\mathrm{t})
$$

We assume that there are constants $\mathrm{k}>0, \alpha>0$ such that for all $\sigma \in \mathrm{E}$

$$
|\mathrm{T}(\mathrm{t}, \sigma)| \leq \mathrm{ke}^{-\alpha(\mathrm{t}-\sigma)}, \mathrm{t} \geq \sigma
$$

We apply Theorem 3.4 and Corollary 3.5 to conclude that (61) is complete. Since the solution operator of (60) apply satisfies relation (62), we apply Theorem 3.4 to show that (61) is Euclidean space null-controllable.

\section{Game of Pursuit Results:}

We investigate a game whose state space is the Sobolev space, $\mathrm{W}_{2}^{(1)}$, with dynamical equation:

$$
\dot{x}(t)=g\left(t, x_{t}\right)-p(t)+q(t), \quad t \in[\sigma, \infty)
$$

where $\mathrm{p} \in \mathrm{L}_{2}([\sigma, \mathrm{t}], \mathrm{P}), \mathrm{P} \subseteq \mathrm{E}^{\mathrm{m}}, \mathrm{q} \in \mathrm{L}_{2}([\sigma, \infty), \mathrm{Q}), \mathrm{Q} \subseteq \mathrm{E}^{\mathrm{m}}$. With the aabove assumptions, given $\sigma, \mathrm{t} \in \mathrm{E}$ and $\varphi \in \mathrm{W}_{2}^{(1)}$ there exist an absolutely continuous function $\mathrm{x}(\cdot, \sigma, \varphi, \mathrm{p}, \mathrm{q}):\left[\sigma-\mathrm{r}, \mathrm{t}_{1}\right] \rightarrow \mathrm{E}^{\mathrm{n}}$ which satisfies (63) a.e. on $\left[\sigma, t_{1}\right]$ with initial condition $\mathrm{x}_{\sigma}=\varphi$. The solution to (63) is given by:

$$
x_{t}(\sigma, \varphi, p, q)=x_{t}(\sigma, \varphi)-\int_{\sigma}^{t} T(t, s) Y_{0}[p(s)-q(s)] d s
$$

where $\mathrm{t} \geq \sigma, \varphi \in \mathrm{W}_{2}^{(1)}$ and $\mathrm{x}(\sigma, \varphi)$ is the solution of (23).

Definition 4.1

There is complete Euclidean space capture everywhere at time $t_{1}$ for game (63) if for each $\varphi \in \mathrm{W}_{2}^{(1)}, \mathrm{x}_{1} \in \mathrm{E}^{\mathrm{n}}$ and for quarry control $\mathrm{q} \in \mathrm{L}_{2}$ there exist pursuer strategy $\mathrm{p} \in \mathrm{L}_{2}$ subject to the following

i) foreach $t \in\left[\sigma, t_{1}\right], p(t)$ depends on $q(t), t_{1}, \varphi$ and $g\left(t, x_{t}\right)$;

ii) the pair of controls so obtained is such that the solution of (63) satisfies $x\left(t_{1}\right)=x_{1}$ and $x_{\sigma}=\varphi$. 
There is Euclidean space capture in zero at time $t_{1}$ or game (63) if the assumptions in Definition 4.1 are met with $\mathrm{x}_{1}=0$. Assosiated with our game is a nonlinear control equation:

$$
\dot{x}(t)=g\left(t, x_{t}\right)-u(t)
$$

where $\mathrm{u} \in \mathrm{L}_{2}([-\mathrm{r}, 0], \mathrm{U})$ and the control set is the Pontryagin difference of sets as given in Hajek [8],

$$
\mathrm{U}=\mathrm{P} \underset{*}{ } \mathrm{Q}=\{\mathrm{x}: \mathrm{x}+\mathrm{Q} \subseteq \mathrm{P}\} .
$$

Theorem 4.2

Assume $0 \in \mathrm{Q}$ and $\mathrm{P}$ compact. There is complete Euclidean space capture everywhere at time $\mathrm{t}_{1}$ for game (63) if, and only if the associated nonlinear control system

$$
\begin{aligned}
& \dot{\mathrm{x}}(\mathrm{t})=\mathrm{g}\left(\mathrm{t}, \mathrm{x}_{\mathrm{t}}\right)-\mathrm{u}(\mathrm{t}) \\
& \mathrm{u}(\mathrm{t}) \in \mathrm{U}=(\mathrm{P}+\operatorname{ker} \mathrm{T}(\mathrm{t}, \mathrm{s})) \underline{*} \mathrm{Q}
\end{aligned}
$$

is Euclidean space controllable at time $t_{1}$. Furthermore, $\alpha(q, t)=u(t)+q$ modulo ker $T(t, s)$ for all $q \in Q$ and $\mathrm{t} \epsilon\left[\sigma, \mathrm{t}_{1}\right]$ can be used to determine a suitable strategy $\mathrm{u} \in \mathrm{L}_{2}\left(\left[\sigma, \mathrm{t}_{1}\right], \mathrm{U}\right)$ in $(67)$ and vice versa.

Remark 4.3

In (67) $\varphi$ is the initial function that is forced to the target by $\alpha$ and $q$.

Proof of Theorem 4.2

Assume there is complete Euclidean space capture everywhere at time $t_{1}$ for game (63). There is a mapping $\alpha: \mathrm{Qx}\left[\sigma, \mathrm{t}_{1}\right] \rightarrow$ Psuch that for any quarry control $\mathrm{q} \in \mathrm{L}_{2}$ the map $\mathrm{p}(\mathrm{t})=\alpha(\mathrm{q}(\mathrm{t}), \mathrm{t})$ is a pursuer strategy; $p$ and $q$ steer arbitrary $\varphi \in \mathrm{W}_{2}^{(1)}$ to any $\mathrm{x}_{1} \in \mathrm{E}^{\mathrm{n}}$ in time $\mathrm{t}_{1}$.

$$
x\left(t_{1}, \sigma, \varphi, p, q\right)=x_{1}=x\left(t_{1}, \sigma, \varphi\right)-\int_{\sigma}^{t_{1}} T\left(t_{1}, s\right) Y_{0}[p(s)-q(s)] d s
$$

or

$$
\mathrm{x}\left(\mathrm{t}_{1}, \sigma, \varphi\right)=\mathrm{x}_{1}+\int_{\sigma}^{\mathrm{t}_{1}} \mathrm{~T}\left(\mathrm{t}_{1}, \mathrm{~s}\right) \mathrm{Y}_{0}[\mathrm{p}(\mathrm{s})-\mathrm{q}(\mathrm{s})] \mathrm{ds}
$$

For quarry control $0 \in \mathrm{Q}$,

$$
x\left(t_{1}, \sigma, \varphi\right)=x_{1}+\int_{\sigma}^{t_{1}} T\left(t_{1}, s\right) Y_{0} u(s) d s
$$

where $\mathrm{u}(\mathrm{s})=\alpha(0, \mathrm{~s})$.

Now take any point $q \in Q$ and time $t \in\left[\sigma, t_{1}\right]$, consider the piecewise constant quarry control such that it is zero on the interval $[\sigma, t)$ and $q$ on the interval $\left[t, t_{1}\right]$.We apply these values in equation (69) to obtain

$$
x\left(t_{1}, \sigma, \varphi\right)=x_{1}+\int_{\sigma}^{t} T\left(t_{1}, s\right) Y_{0} u(s) d s+\int_{t}^{t_{1}} T\left(t_{1}, s\right) Y_{0}[\alpha(q, s)-q] d s .
$$

Subtact (71) from (70) to obtain

$$
\begin{aligned}
& \int_{t}^{t_{1}} T\left(t_{1}, s\right) Y_{0}[u(s)+q-\alpha(q, s)] d s=0 \\
& T\left(t_{1}, s\right) Y_{0}[u(s)+q-\alpha(q, s)]=0
\end{aligned}
$$

for almost all $s \in\left[\sigma, \mathrm{t}_{1}\right]$.We use the kernel to interprete this as

$$
u(s)+q \epsilon\left[\alpha(q, s)+\operatorname{ker} T\left(t_{1}, s\right) Y_{0}\right]
$$

Because $\alpha$ has values in $\mathrm{P}, \mathrm{u}(\mathrm{s})+\mathrm{q} \in\left[\mathrm{P}+\operatorname{ker} \mathrm{T}\left(\mathrm{t}_{1}, \mathrm{~s}\right) \mathrm{Y}_{0}\right]$. Since the right side of (74) is closed, we use Hajek's lemma [8, p.59] to obtain

$$
u(s)+Q \subseteq\left[P+\operatorname{ker} T\left(t_{1}, s\right) Y_{0}\right] \text { a.e. }
$$


or

$$
\mathrm{u}(\mathrm{s}) \in\left[\mathrm{P}+\mathrm{T}\left(\mathrm{t}_{1}, \mathrm{~s}\right) \mathrm{Y}_{0}\right] \underline{*} \mathrm{Q} \equiv \mathrm{U}(\mathrm{s}) \text { a.e. }
$$

So that $\mathrm{u} \in \mathrm{L}_{2}\left(\left[\sigma, \mathrm{t}_{1}\right], \mathrm{U}\right)$. Hence $\mathrm{u}$ is an admissible control for (67) and (70)to yield

$$
\mathrm{x}\left(\mathrm{t}_{1}, \sigma, \varphi\right)=\mathrm{x}_{1}+\int_{\sigma}^{\mathrm{t}_{1}} \mathrm{~T}\left(\mathrm{t}_{1}, \mathrm{~s}\right) \mathrm{Y}_{0} \mathrm{u}(\mathrm{s}) \mathrm{ds}
$$

or

$$
x_{1}=x\left(t_{1}, \sigma, \varphi\right)-\int_{\sigma}^{t_{1}} T\left(t_{1}, s\right) Y_{0} u(s) d s
$$

Note that $\mathrm{x}_{\sigma}=\varphi$ and (74) proves (67).

Conversely, assume that (67) is Euclidean space controllable at time $t_{1}$, let $\varphi \in \mathrm{W}_{2}^{(1)}$ and $\mathrm{x}_{1} \in \mathrm{E}^{\mathrm{n}}$ be given. Let $\mathrm{u}$ be the appropriate control in $\mathrm{L}_{2}$ such that $\mathrm{x}_{\sigma}=\varphi, \mathrm{x}\left(\mathrm{t}_{1}\right)=\mathrm{x}_{1}$. Then

$$
x_{1}=x\left(t_{1}, \sigma, \varphi\right)-\int_{\sigma}^{t_{1}} T\left(t_{1}, s\right) Y_{0} u(s) d s
$$

where $u(s) \in U$ yields $u(s)+q \in\left[P+\operatorname{ker} T\left(t_{1}, s\right) Y_{0}\right]$. We now apply Fillipov's lemma [8, p.110] to construct pursuer control: there exist measurable mappings

$$
\alpha: \mathrm{Q} \times\left[\sigma, \mathrm{t}_{1}\right] \rightarrow \mathrm{P}, \mathrm{l}: \mathrm{Q} \times\left[\sigma, \mathrm{t}_{1}\right] \rightarrow \operatorname{ker} \mathrm{T}\left(\mathrm{t}_{1}, \mathrm{~s}\right) \mathrm{Y}_{0}
$$

such that

$$
\mathrm{u}(\mathrm{s})+\mathrm{q} \equiv \alpha(\mathrm{q}, \mathrm{s})+\mathrm{l}(\mathrm{q}, \mathrm{s})
$$

Because $\alpha$ takes values in a compact set $\mathrm{P}, \alpha \in \mathrm{L}_{2}\left(\left[\sigma, \mathrm{t}_{1}\right], \mathrm{P}\right)$. We now how that for any quarry control $\mathrm{q}, \alpha$ is indeed appropriate.

For any $q \in L_{2}\left(\left[\sigma, t_{1}\right], Q\right), \alpha-q=u-l$, so that the solution at $t_{1}$ of (63) with this pair of $\alpha$ and $q$ with initial function $\varphi$ is:

$$
\begin{aligned}
& \mathrm{x}\left(\mathrm{t}_{1}, \sigma, \varphi, \alpha, q\right)= \mathrm{x}\left(\mathrm{t}_{1}, \sigma, \varphi\right)-\int_{\sigma}^{\mathrm{t}_{1}} \mathrm{~T}\left(\mathrm{t}_{1}, \mathrm{~s}\right) \mathrm{Y}_{0}[\alpha(\mathrm{q}, \mathrm{s})-\mathrm{q}] \mathrm{ds} \\
&=\mathrm{x}\left(\mathrm{t}_{1}, \sigma, \varphi\right)-\int_{\sigma}^{\mathrm{t}_{1}} \mathrm{~T}\left(\mathrm{t}_{1}, \mathrm{~s}\right) \mathrm{Y}_{0}[\mathrm{u}(\mathrm{s})-\mathrm{l}(\mathrm{q}, \mathrm{s})] \mathrm{ds} \\
&=\mathrm{x}\left(\mathrm{t}_{1}, \sigma, \varphi\right)-\int_{\sigma}^{\mathrm{t}_{1}} \mathrm{~T}\left(\mathrm{t}_{1}, \mathrm{~s}\right) \mathrm{Y}_{0} \alpha(\mathrm{q}, \mathrm{s}) \mathrm{ds}-\int_{\sigma}^{\mathrm{t}_{1}} \mathrm{~T}\left(\mathrm{t}_{1}, \mathrm{~s}\right) \mathrm{Y}_{0} \mathrm{u}(\mathrm{s}) \mathrm{ds} \\
&=\mathrm{x}_{1}+0 .
\end{aligned}
$$

This completes the proof.

Theorem 4.2

In game (63) assume $0 \in \mathrm{Q}, \mathrm{P}$ compact. Ttthen there is complete function space capture everywhere at time $t_{1}$ for (67) if, and only if, the associated nonlinear control equation:

$$
\begin{aligned}
& \dot{x}(t)=g\left(t, x_{t}\right)-u(t), t \geq \sigma \\
& x_{\sigma}=\varphi \in W_{2}^{(1)}\left([-r, 0], E^{n}\right), u(t) \in U \\
& U=\left[P+\operatorname{ker} T\left(t_{1}, s\right) Y_{0}\right] \underset{*}{U}
\end{aligned}
$$

Is controllable at time $t_{1}$. Furthermore, $\alpha(q, s)=u(s)+q$ modulo $\operatorname{ker} T\left(t_{1}, s\right) Y_{0}$, for all $q \in Q, s \in\left[\sigma, t_{1}\right]$ can be used to determine a suitable control strategy from admissible control $u \in L_{2}([\sigma, t], U)$ for $(67)$ and vice versa.

The proof is quite similar to that of theorem 4.1 .

\section{Conclusion}

We notice that we have employed nonlinear variation of constants formula as developed by Shanholt to arrive at similar results such as that developed by Chukwu, et al for Euclidean and function space controllability. We also establish similar results for nonlinear differential games of pursuit. 


\section{References}

[1]. Hermes,H. and Lasalle,J.P., Functional Analysis and Time Optimal ControlAcademic Press, 1969.

[2]. Chukwu, E. N.,On null-controllability of nonlinear delay systems with restrained controls, J. Math. Anal. Appl. Vol.76, no. 1, July 1980

[3]. ---------, Capture in linear functional differential games of pursuit, J. Math. Anal. Appl., Vol. 70, No.

[4]. Shanholt, G. A., A nonlinear variation of constants formula for functional differential equations, Math. Systems theory, Vol. 6, No. 4, 1972-1973.

[5]. Chukwu, E. N., Null-controllability in function space of nonlinear retarded systems with limited control.

[6]. Hale, J., Functional Differential Equations Springer- Verlag, New York, 1971

[7]. Luenberger, D. G., Optimization of vector space method John Wiley, New York, 1969

[8]. Hajek,O., Pursuit Games Academic Press, New York, 1975. 